\title{
AkMen
}

Volume 17 Nomor 3 September 2020

Hal. $393-407$

e-ISSN : 2621-4377 \& p-ISSN : 1829-8524

Hbmepage: https//e-jurnal.stienobel-indonesia.acid/index.php/akmen

\section{PENGARUH LINGKUNGAN KERJA, KOMPENSASI, DAN MOTIVASI TERHADAP KINERJA KARYAWAN MELALUI KEPUASAN KERJA PADA PT MATAHARI DEPARTEMENT STORE CABANG MALL PANAKUKANG MAKASSAR}

\author{
Nafila Oktavia, Syamsul Alam, Asri \\ STIE NOBEL INDONESIA \\ Nafilah.oktavia@yahoo.com, syamsulalam@stienobel-indonesia.ac.id, asri@stienobel-indonesia.ac.id
}

\begin{abstract}
ABSTRAK
Penelitian ini bertujuan untuk mengetahui Pengaruh lingkungan kerja, kompensasi, motivasi terhadap terhadap kinerja karyawan melalui kepuasan kerja pada PT Matahari Departement Store cabang Mall Panakukang Makassar.

Populasi yang digunakan dalam penelitian ini adalah karyawan PT Matahari Departement Store cabang Mall Panakukang Makassar yang berjumlah 100 orang. sedangkan sampel ditentukan berdasarkan ketentuan sampel jenuh, yang mengambil semua elemen populasi untuk menjadi sampel penelitian. Metode analisis yang digunakan adalah analisis jalur.

Hasil penelitian menunjukkan (1) Lingkungan kerja, kompensasi, dan motivasi berpengaruh positif dan signifikan terhadap kepuasan kerja karyawan pada PT Matahari Departement Store Cabang Mall Panakkukang Makassar (2) Lingkungan kerja, kompensasi, dan motivasi berpengaruh positif dan signifikan terhadap kinerja karyawan pada PT Matahari Departement Store Cabang Mall Panakkukang Makassar (3) Lingkungan kerja, kompensasi, dan motivasi berpengaruh positif dan signifikan terhadap kinerja karyawan melalui kepuasan kerja pada PT Matahari Departement Store Cabang Mall Panakkukang Makassar.

Kata kunci: Lingkungan Kerja, Kompensasi, Motivasi Kepuasan Kerja dan Kinerja Karyawan
\end{abstract}

\begin{abstract}
ABSTRACK
This study aims to determine the effect of work environment, compensation, motivation on employee performance through job satisfaction at PT Matahari Department Store, Mall Panakukang Makassar branch.

The population used in this study were 100 employees of PT Matahari Department Store, Panakukang Mall Makassar branch. While the sample is determined based on the provisions of the saturated sample, which takes all elements of the population to be the research sample. The analytical method used is path analysis.

The results showed (1) Work environment, compensation, and motivation have a positive and significant effect on employee job satisfaction at PT Matahari Department Store, Mall Panakkukang Makassar Branch (2) Work environment, compensation, and motivation have a positive and significant effect on employee performance at PT Matahari Department Store Branch Mall Panakkukang Makassar (3) Work environment, compensation, and motivation have a positive and significant effect on employee performance through job sati.
\end{abstract}

Keywords: Work Environment, Compensation, Job Satisfaction Motivation and Employee Performance

\section{PENDAHULUAN}

Kemajuan pesat dalam ilmu pengetahuan dan teknologi telah mendorong perkembangan kemajuan, membuka masa depan, dan memberi harapan kehidupan perusahaan di masa yang datang. Hal tersebut mengakibatkan adanya berbagai keterbukaan di semua kehidupan masyarakat di dunia, sehingga menimbulkan persaingan. Berkaitan dengan hal tersebut, maka 
hanya di negara yang memiliki sumber daya manusia yang berkualitas yang mampu memenangkan persaingan tersebut, karena kunci kemampuan daya saing adalah manusia yang berkualitas akan mampu menciptakan keunggulan kompetitif.

Dalam konteks bisnis, kualitas sumber daya manusia merupakan faktor fundamental yang berperan penting untuk mencapai keunggulan bersaing suatu perusahaan. Keunggulan tersebut dapat dicapai dengan pengelolaan sumber daya manusia yang efektif dan efisien. Dampak dari pengelolaan tersebut secara langsung dapat terlihat pada kinerja sumber daya manusia, yang juga berimbas pada perbaikan atau peningkatan kinerja perusahaan secara keseluruhan. Pengelolaan yang baik juga dapat dinilai dari besarnya pertumbuhan laba perusahaan yang mampu dihasilkan dalam kurun waktu tertentu.

Menurut Prawirosentono (Sinambela, 2019) kinerja karyawan dipandang sebagai hasil kerja yang dapat dicapai oleh seseorang atau sekelompok orang dalam suatu organisasi, sesuai dengan wewenang dan tanggung jawab masing-masing, dalam rangka upaya mencapai tujuan organisasi bersangkutan secara legal, tidak melanggar hukum dan sesuai dengan moral dan etika. Dengan kata lain kinerja adalah tingkat keberhasilan seseorang dalam melaksanakan pekerjaannya. Tercapai tidaknya tujuan organisasi sangat ditentukan sejauh mana pemahaman dan penerimaan karyawan tentang tujuan organisasi/perusahaan. Yang dimaksud tujuan organissi adalah suatu target yang hendak dicapai oleh organisasi dalam kurun waktu tertentu.

Tentunya tidak mudah mencapai kinerja karyawan yang optimal dan berkesinambungan. Diperlukan kajian-kajian mengenai berbagai faktor yang dapat memengaruhi setiap elemen dari kinerja karyawan tersebut. Seperti faktor lingkungan kerja karyawan, faktor kompensasi yang diterima karyawan dari perusahaan, faktor motivasi karyawan, dan juga faktor kepusasan kerja karyawan terhadap perusahaan. Berbagai faktor tersebut dapat dikaji lebih dalam untuk melihat manakah yang harus diprioritaskan terlebih dahulu untuk mengetahui faktor manakah yang berdominan lebih berpengaruh terhadap meningkatkan keberhasilan kinerja karyawan untuk mencapai tujuan perusahaan.

Lingkungan kerja, kompensasi, serta motivasi merupakan faktor-faktor penting yang dapat dikaji secara ilmiah mengenai dampaknya terhadap kinerja karyawan. Namun disisi lain, faktor kepuasan kerja karyawan juga menjamin tinggi rendahnya hasil kerja yang dihasilkan karyawan tersebut. Kepuasan kerja merupakan hal penting yang dimiliki individu di dalam bekerja. Setiap individu pekerja memiliki karateristik yang berbeda-beda, maka tingkat kepuasan kerjanya bebrbeda-beda pula. Tinggi rendahnya kepuasan kerja tersebut dapat memberikn dampak yang tidak sama. Menurut Roe dan Byars (Priansa, 2018) menyatakan bahwa kepuasan kerja yang tinggi akan mendorong terwujudnya tujuan organisasi secara efektif. Sementara tingkat kepuasan kerja yang rendah merupakan ancaman yang akan membawa kehancuran atau kemunduran bagi organisasi, secara cepat ataupun perlahan.

Dalam penelitian ini, identifikasi variabel-variabel penelitian dapat dibedakan menjadi 2 jenis variabel. Pertama, variabel independent dalam penelitian terbagi atas tiga yaitu lingkungan kerja (X1) kompensasi (X2), dan motivasi (X3) variabel dependen 1 dalam penelitian ini adalah kepuasan kerja (Y1), dan variabel dependen 2 adalah kinerja karyawan (Y2). Untuk lebih jelasnya mengenai kerangka konseptual penelitian ini, peneliti memaparkan gambaran lengkap mengenai variabel-variabel penelitian serta hubungannya seperti pada gambar kerangka konseptual berikut: 


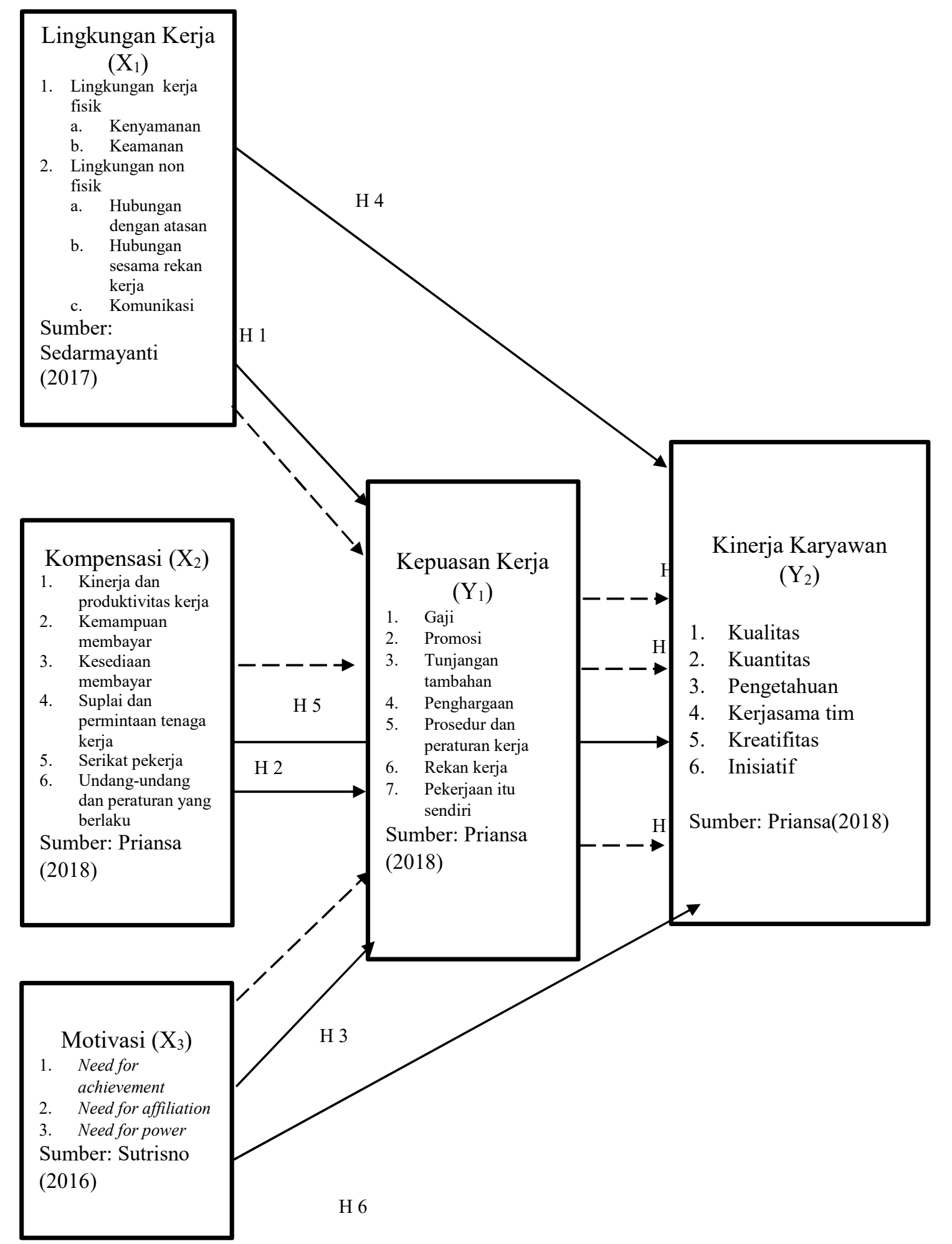

\section{Kerangka Konseptual}




\section{METODE PENELITIAN}

Penelitian ini dilakukan dengan menggunakan metode survey, yaitu kegiatan mengumpulkan data mengenai fakta-fakta yang merupakan pendukung terhadap penelitian mengenai lingkungan kerja, motivasi dan kompensasi terhadap kepuasan kerja karyawan dengan cara membandingan standar yang sudah ditentukan.

Jenis penelitian ini adalah penelitian asosiatif dengan menggunakan pendekatan deskriptif kuantitatif. Penelitian asosiatif kausal adalah penelitian yang bertujuan untuk mengetahui pengaruh antara dua variabel atau lebih. Penelitian ini akan menjalankan hubungan mempengaruhi dan dipengaruhi dari variabel-variabel yang akan diteliti. Menurut Echdar (2017). Pendekatan kuantitatif adalah metode yang lebih menekankan pada aspek pengukuran secara objektif terhadap fenomena social, dan dijabarkan dalam beberapa komponen masalah, variabel dan indikator, dan setiap variabel yang ditentukan diukur dengan memberikan simbol-simbol angka yang berbeda sesuai dengan kategori informasi yang berkaitan dengan variabel tersebut.

\section{HASIL PENELITIAN DAN PEMBAHASAN Uji Validitas}

\begin{tabular}{|c|c|c|c|c|}
\hline Variabel & Item Variabel & R Hitung & $\mathbf{R}$ Tabel & Keterangan \\
\hline \multirow{5}{*}{ Lingkungan Kerja } & Item 1 & 0,654 & 0,199 & Valid \\
\hline & Item 2 & 0,689 & 0,199 & Valid \\
\hline & Item 3 & 0,668 & 0,199 & Valid \\
\hline & Item 4 & 0,773 & 0,199 & Valid \\
\hline & Item 5 & 0,630 & 0,199 & Valid \\
\hline \multirow{6}{*}{ Kompensasi } & Item 1 & 0,510 & 0,199 & Valid \\
\hline & Item 2 & 0,723 & 0,199 & Valid \\
\hline & Item 3 & 0,638 & 0,199 & Valid \\
\hline & Item 4 & 0,543 & 0,199 & Valid \\
\hline & Item 5 & 0,756 & 0,199 & Valid \\
\hline & Item 6 & 0,664 & 0,199 & Valid \\
\hline \multirow{6}{*}{ Motivasi } & Item 1 & 0,667 & 0,199 & Valid \\
\hline & Item 2 & 0,627 & 0,199 & Valid \\
\hline & Item 3 & 0,628 & 0,199 & Valid \\
\hline & Item 4 & 0,600 & 0,199 & Valid \\
\hline & Item 5 & 0,438 & 0,199 & Valid \\
\hline & Item 6 & 0,509 & 0,199 & Valid \\
\hline \multirow{7}{*}{ Kepuasan Kerja } & Item 1 & 0,479 & 0,199 & Valid \\
\hline & Item 2 & 0,595 & 0,199 & Valid \\
\hline & Item 3 & 0,595 & 0,199 & Valid \\
\hline & Item 4 & 0,582 & 0,199 & Valid \\
\hline & Item 5 & 0,523 & 0,199 & Valid \\
\hline & Item 6 & 0,537 & 0,199 & Valid \\
\hline & Item 7 & 0,507 & 0,199 & Valid \\
\hline \multirow{4}{*}{ Kinerja Karyawan } & Item 1 & 0,702 & 0,199 & Valid \\
\hline & Item 2 & 0,729 & 0,199 & Valid \\
\hline & Item 3 & 0,729 & 0,199 & Valid \\
\hline & Item 4 & 0,733 & 0,199 & Valid \\
\hline
\end{tabular}




\begin{tabular}{|c|c|c|c|c|}
\hline Variabel & Item Variabel & R Hitung & R Tabel & Keterangan \\
\hline & Item 5 & 0,695 & 0,199 & Valid \\
\cline { 2 - 5 } & Item 6 & 0,637 & 0,199 & Valid \\
\hline
\end{tabular}

Hasil pengujian validitas kuesioner penelitian yang ditunjukkan tabel 5.8 dapat dinyatakan bahwa nilai $r$ hitung semua item dalam kuesioner penelitian $>$ nilai $r$ tabel, hal tersebut berarti item-item kuesioner penelitian yang digunakan valid atau layak.

\section{Uji Reliabilitas}

\begin{tabular}{|l|c|c|c|}
\hline \multicolumn{1}{|c|}{ Variabel } & Cronbach's Alpha & Nilai Batas & Keterangan \\
\hline Lingkungan Kerja $\left(\mathrm{X}_{1}\right)$ & 0,715 & 0,6 & Reliabel \\
\hline Kompensasi $\left(\mathrm{X}_{2}\right)$ & 0,702 & 0,6 & Reliabel \\
\hline Motivasi $\left(\mathrm{X}_{3}\right)$ & 0,602 & 0,6 & Reliabel \\
\hline Kepuasan Kerja ( $\left.\mathrm{Y}_{1}\right)$ & 0,606 & 0,6 & Reliabel \\
\hline Kinerja Karyawan $\left(\mathrm{Y}_{2}\right)$ & 0,792 & 0,6 & Reliabel \\
\hline
\end{tabular}

Sumber: Data primer diolah SPSS 26, 2020.

Hasil pengujian reliabilitas yang ditunjukkan tabel di atas dapat dinyatakan bahwa nilai Cronbach's Alpha semua variabel dalam penelitian ini $>$ nilai batas $(0,6)$. Hal tersebut berarti variabel-variabel dalam kuesioner penelitian memenuhi kriteria reliabilitas dan berarti kuesioner penelitian reliabel atau handal sebagai alat pengumpul data.

\section{Uji Normalitas}

\begin{tabular}{|c|c|c|}
\hline \multicolumn{3}{|c|}{ One-Sample Kolmogorov-Smirnov Test } \\
\hline & & Unstandardized Residual \\
\hline $\mathrm{N}$ & & 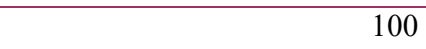 \\
\hline \multirow[t]{2}{*}{ Normal Parameters ${ }^{\mathrm{a}, \mathrm{b}}$} & Mean & 0,0000000 \\
\hline & Std. Deviation & 0,58728518 \\
\hline \multirow[t]{3}{*}{ Most Extreme Differences } & Absolute & 0,062 \\
\hline & Positive & 0,043 \\
\hline & Negative & $-0,062$ \\
\hline Test Statistic & & 0,062 \\
\hline Asymp. Sig. (2-tailed) & & $.200^{\mathrm{c}, \mathrm{d}}$ \\
\hline \multicolumn{3}{|c|}{$\begin{array}{l}\text { a. Test distribution is Normal. } \\
\text { b. Calculated from data. } \\
\text { c. Lilliefors Significance Correction. } \\
\text { d. This is a lower bound of the true significance. }\end{array}$} \\
\hline
\end{tabular}

Sumber: Data primer diolah SPSS 26, 2020.

Hasil pengujian normalitas dengan menggunakan Kolmogorov-Smirnov test yang ditampilkan tabel di atas dapat dijelaskan bahwa data penelitian ini memenuhi kriteria 


\section{AkMen}

Volume 17 Nomor 3 September 2020

Hal. $393-407$

e-ISSN : 2621-4377 \& p-ISSN : 1829-8524

Hbmepage: https//e-jurnal.stiendbel-indonesia.acid/index.php/akmen

pengujian normalitas. Hal tersebut disebabkan nilai signifikansi 0,200 >0,05, maka data penelitian ini dapat dilanjutkan ke pengujian regresi linear berganda.

\section{Uji Multikolinieritas}

\begin{tabular}{|c|c|c|c|}
\hline \multicolumn{4}{|c|}{ Coefficients $^{\mathrm{a}}$} \\
\hline \multirow[t]{2}{*}{ Model } & & \multicolumn{2}{|c|}{ Collinearity Statistics } \\
\hline & & Tolerance & VIF \\
\hline 1 & (Constant) & & \\
\hline & Lingkungan Kerja & 0,274 & 3,654 \\
\hline & Kompensasi & 0,219 & 4,560 \\
\hline & Motivasi & 0,176 & 5,678 \\
\hline & Kepuasan Kerja & $\mathbf{0 , 1 3 3}$ & 7,517 \\
\hline
\end{tabular}

Sumber: Data primer diolah SPSS 26, 2020.

Hasil pengujian multkolinieritas di atas dapat dijelaskan sebagai berikut:

1) Nilai tolerance lingkungan kerja $0,274>0,10$, dan nilai VIF 3,654 $<10,00$.

2) Nilai tolerance kompensasi $0,219>0,10$, dan nilai VIF 4,560<10,00.

3) Nilai tolerance motivasi $0,176>0,10$, dan nilai VIF 5,678<10,00.

4) Nilai tolerance kepuasan kerja 0,133 , dan nilai VIF $7,517<10,00$.

Berdasarkan interpretasi di atas dapat disimpulkan bahwa tidak terjadi multikolinieritas pada data yang diuji. Dengan kata lain tidak terjadi korelasi antar variabel independen dalam penelitian ini.

\section{Uji Heterokedastisitas}

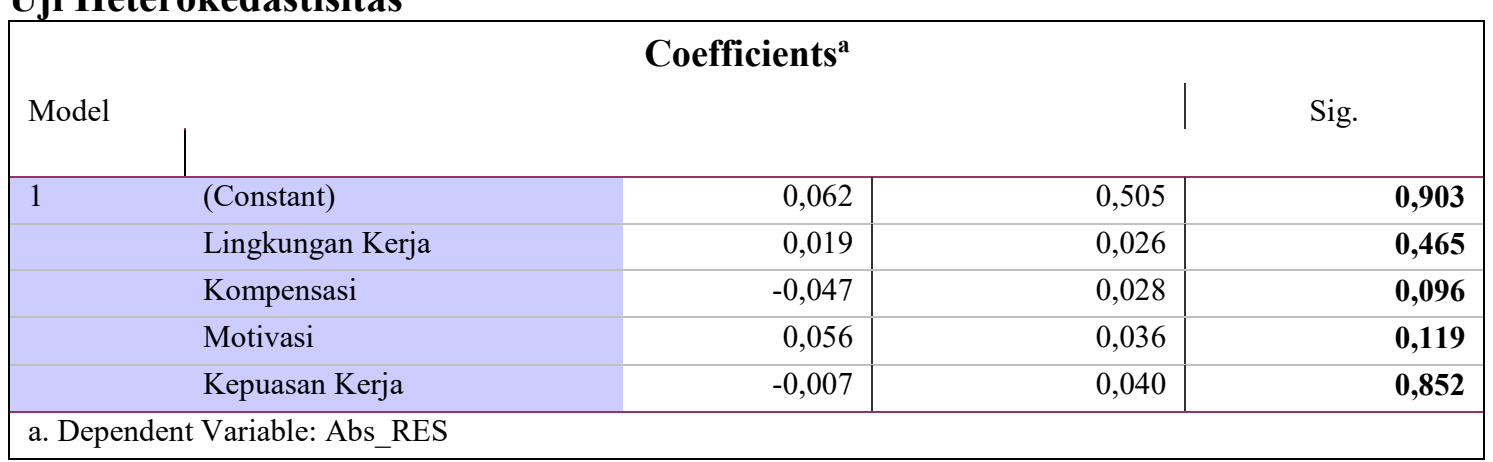

Sumber: Data primer diolah SPSS 26, 2020.

Hasil pengujian heterokedastisitas dalam penelitian ini dapat diinterpretasikan sebagai berikut:

1) Nilai Sig lingkungan kerja $0,465>0,05$

2) Nilai Sig kompensasi $0,096>0,05$

3) Nilai Sig motivasi $0,119>0,05$

4) Nilai Sig kepuasan kerja $0,852>0,05$

Berdasarkan interpretasi nilai dari pengujian heterkekastisitas di atas maka dapat disimpulkan bahwa data penelitian ini memenuhi kriteria pengujian heterkoedastistias karena nilai signifikansi yang dihasilkan dalam pengujian Glejser $>0,05$. 


\section{AkMen}

\section{Analisis Jalur}

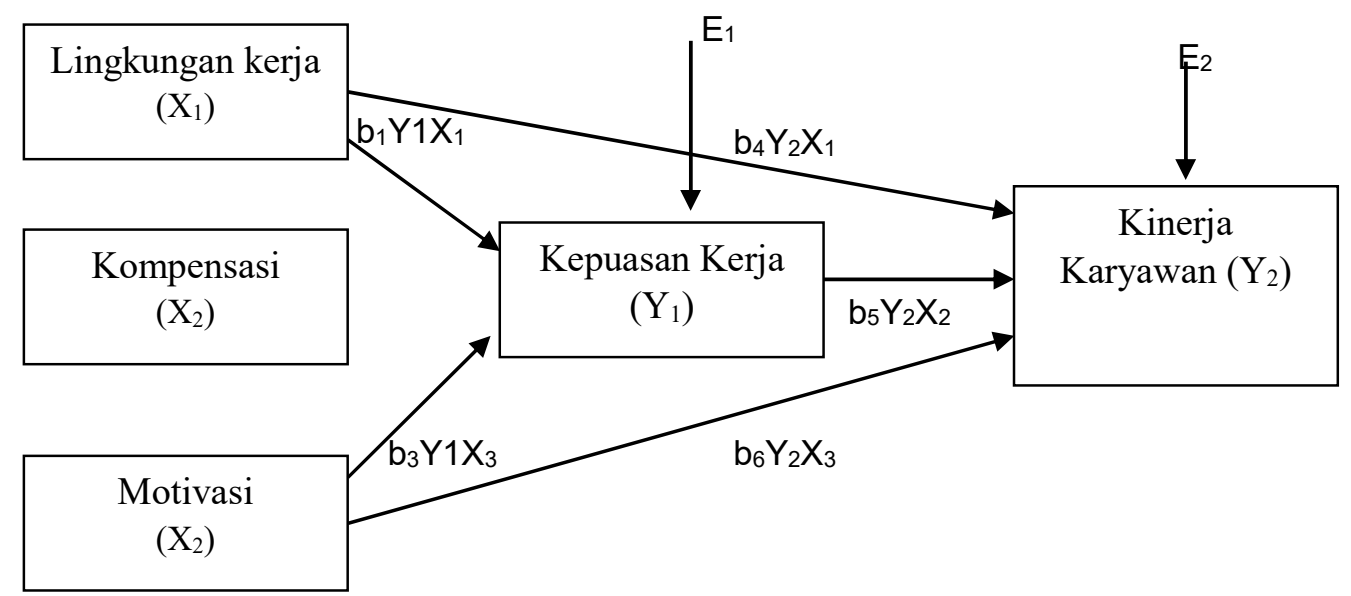

Berdasarkan gambar model analisis jalur di atas dapat diketahui hubungan antar variabel adalah linear, yaitu alur korelasi ke satu arah tidak terjadi pemutaran kembali (looping) dapat dibuat persamaan struktural analisis jalur yang meliputi $\mathrm{X}_{1}, \mathrm{X}_{2}$ sebagai variable bebas (variabel eksogen), kepuasan kerja sebagai variable terikat 1 ( $\left.\mathrm{Y}_{1}\right)$, kinerja karyawan sebagai variabel terikat $2\left(\mathrm{Y}_{2}\right)$ sebagai variable terikat (variabel endogen) dan $\mathrm{E}=$ Error sebagai berikut:

1. Persamaan substruktur pertama

$$
\mathrm{Y} 1=\mathrm{b}_{1} \mathrm{Y}_{1} \mathrm{X}_{1}+\mathrm{b}_{2} \mathrm{Y}_{1} \mathrm{X}_{2}+\mathrm{b}_{3} \mathrm{Y}_{1} \mathrm{X}_{3}+\mathrm{E}_{1}
$$

2. Persamaan substruktur kedua

$$
\mathrm{Y} 2=\mathrm{b}_{4} \mathrm{Y}_{2} \mathrm{X}_{1}+\mathrm{b}_{5} \mathrm{Y}_{1} \mathrm{Y}_{2}+\mathrm{b}_{6} \mathrm{Y}_{2} \mathrm{X}_{2}+\mathrm{b}_{7} \mathrm{Y}_{2} \mathrm{X}_{3}+\mathrm{E}_{2}
$$

Melakukan pemeriksaan terhadap asumsi yang melandasi analisis jalur, yaitu hubungan antar variabel adalah linier dan aditif. Berdasarkan gambar 5.2 Maka dapat dijelaskan hubungan antar variabel adalah linier, yaitu sistem aliran ke satu arah, tidak ada variabel dependen (endogen) yang mempunyai pengaruh bolak balik.

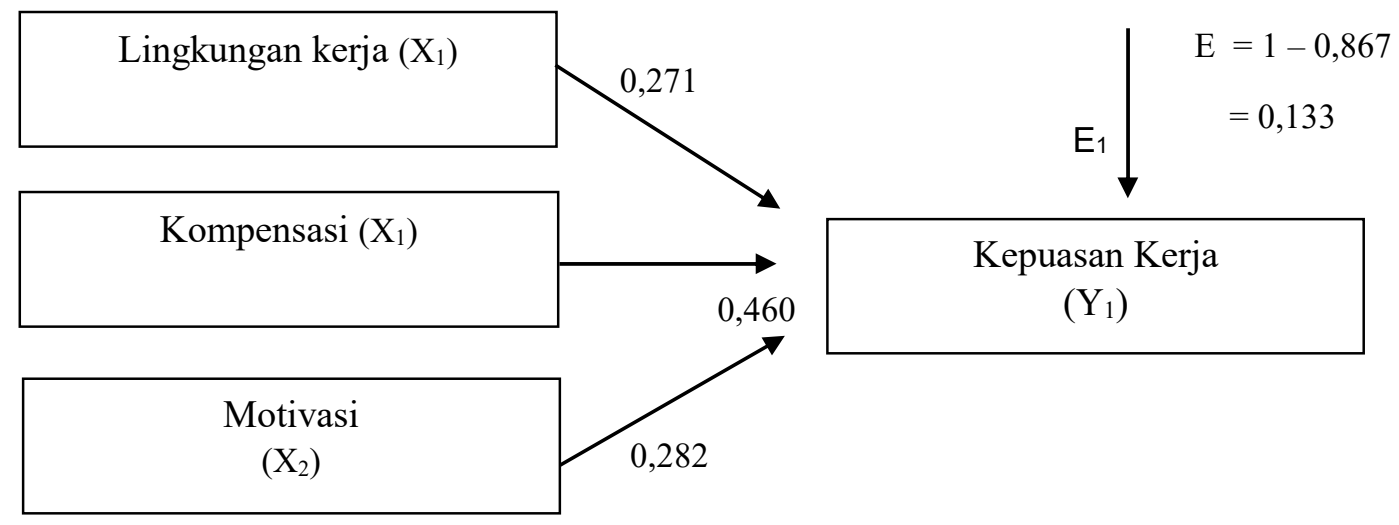

Gambar Hasil Estimasi Jalur Sub Struktur Pertama 
Adapun sub struktur pertama pengaruh lingkungan kerja, kompensasi, dan motivasi terhadap kepuasan kerja PT Matahari Departement Store Cabang Mall Panakkukang Makassar:

$Y_{1}=0,271 X_{1}+0,460 X_{2}+0,282 X_{3}+0,133 E_{1}$

Jadi berdasarkan kriteria pengujian parsial, dapat disimpulkan bahwa lingkungan kerja, kompensasi, motivasi, kepuasan kerja berpengaruh positif dan signifikan secara parsial terhadap kinerja karyawan PT Matahari Departement Store Cabang Mall Panakkukang Makassar. Selanjutnya dalam pemodelan analisis jalur, hasil output dari pengujian parsial dapat dideskripsikan seperti pada gambar berikut ini:

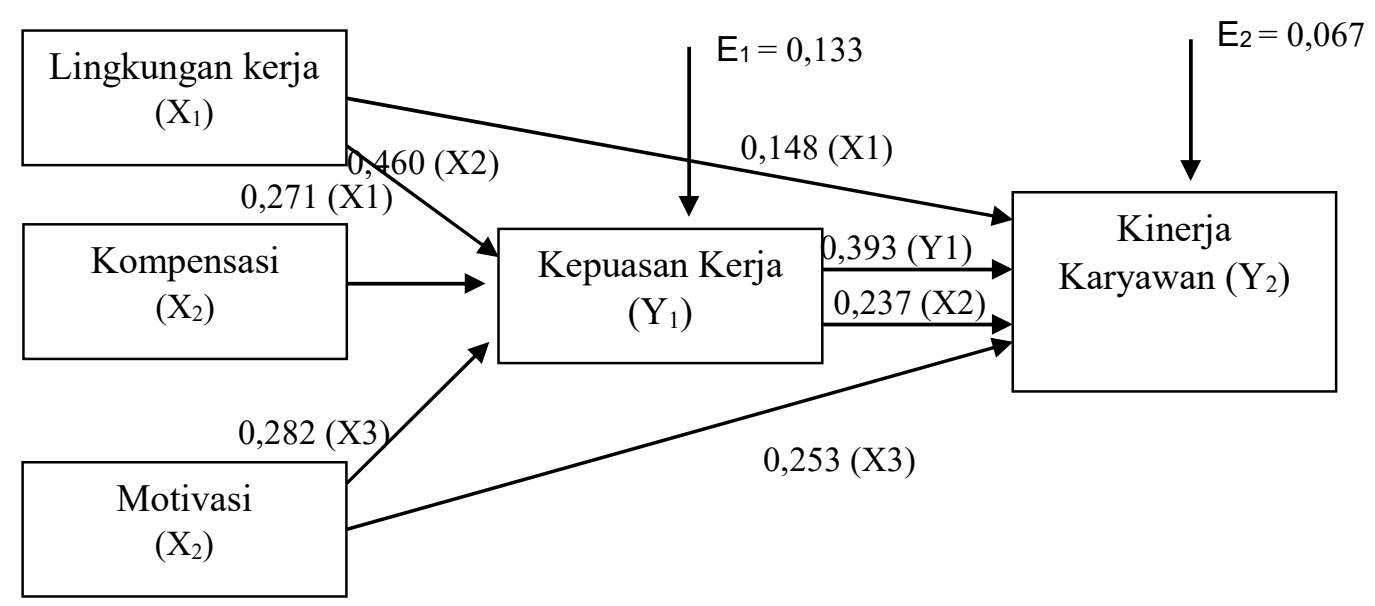

Gambar Hasil Estimasi Jalur Sub Struktur Kedua

Sub struktur kedua pengaruh lingkungan kerja, kompensasi, motivasi, dan kepuasan kerja terhadap kinerja karyawan pada PT Matahari Departement Store Cabang Panakkukang Makassar adalah sebagai berikut:

$Y=0,148 X_{1}+0,237 X_{2}+0,253 X_{3}+0,393 Y_{1}+0,067 E 2$

\section{PEMBAHASAN}

\section{Pengaruh Lingkungan Kerja terhadap Kinerja Karyawan Melalui Kepuasan Kerja}

Berdasarkan hasil pengujian analisis jalur sub struktur pertama menunjukkan bahwa lingkungan kerja berpengaruh positif dan signifikan terhadap kepuasan kerja karyawan pada PT Matahari Departement Store Cabang Mall Panakkukang Makassar dengan tingkat pengaruh sebesar 27,1\%. Pada pengujian analisis jalur sub struktur kedua menunjukkan bahwa lingkungan kerja berpengaruh positif dan signifikan terhadap kinerja karyawan pada PT Matahari Departement Store Cabang Mall Panakkukang Makassar dengan tingkat pengaruh sebesar 14,8\%. Total pengaruh (Total Effect) lingkungan kerja terhadap kinerja karyawan melalui kepuasan kerja dengan tingkat pengaruh sebesar 0,254 atau $25,4 \%$.

Hasil penelitian ini sejalan dengan penelitian lain yang dilakukan oleh Dwijayanti dan Dewi (2015) dengan judul "Pengaruh Kompensasi dan Lingkungan Kerja terhadap 
Kepuasan Kerja Karyawan pada Perusahaan Daerah Air Minum Tirta Mangutama Bandung. Hasil analisis dalam penelitian ini ditemukan bahwa kompensasi dan lingkungan kerja secara parsial berpengaruh positif dan signifikan terhadap kepuasan kerja. Variabel yang paling dominan mempengaruhi kepuasan kerja adalah lingkungan kerja.

Hasil penelitian lain yang juga sejalan dengan penelitian ini adalah penelitian yang dilakukan oleh Simaremare dan Isyandi (2015) dengan judul "Pengaruh Pelatihan, Lingkungan Kerja Fisik dan Kepemimpinan Terhadap Kepuasan Kerja dalam Meningkatkan Kinerja Karyawan Pada PT Federal International Finance Wilayah Riau”. Uji regresi berganda menunjukkan bahwa variabel pelatihan, lingkungan kerja fisik dan kepemimpinan memiliki pengaruh yang signifikan terhadap kepuasan kerja karyawan di Federal International Finance.

Penelitian ini juga sejalan dengan teori yang dikemukakan oleh Sedarmayanti (2017), menurutnya lingkungan kerja merupakan keseluruhan alat perkakas dan bahan yang dihadapi, lingkungan kerja sekitarnya dimana seseorang bekerja, metode kerjanya, serta pengaturan kerjanya baik sebagai perseorangan maupun sebagai kelompok, lingkungan kerja merupakan salah satu faktor yang penting dalam menciptakan kinerja karyawan karena lingkungan kerja mempunyai pengaruh langsung terhadap karyawan didalam menyelesaikan pekerjaan yang ada pada akhirnya akan menignkatkan kinerja organisasi. Suatu kondisi lingkungan kerja dikatakan baik apabila karyawan dapat melaksanakan kegiatan secara optimal, sehat, aman dan nyaman. Maka dari itu penentuan dan pencipta lingkungan kerja yang baik akan sangat menentukan keberhasilan pencapaian tujuan organisasi. Sebaliknya apabila lingkungan kerja tidak baik akan menurutkan motivasi serta semangat kerja karyawan dan pada akhirnya dapat menurunkan kinerja karyawan.

\section{Pengaruh Kompensasi terhadap Kinerja Karyawan Melalui Kepuasan Kerja}

Berdasarkan hasil pengujian analisis jalur sub struktur pertama menunjukkan bahwa kompensasi berpengaruh positif dan signifikan terhadap kepuasan kerja karyawan pada PT Matahari Departement Store Cabang Mall Panakkukang Makassar dengan tingkat pengaruh sebesar $46 \%$. Pada pengujian analisis jalur sub struktur kedua menunjukkan bahwa kompensasi berpengaruh positif dan signifikan terhadap kinerja karyawan pada PT Matahari Departement Store Cabang Mall Panakkukang Makassar dengan tingkat pengaruh sebesar 23,7\%. Total pengaruh (Total Effect) kompensasi terhadap kinerja karyawan melalui kepuasan kerja dengan tingkat pengaruh sebesar 0,417 atau 41,7\%.

Hasil penelitian ini sejalan dengan penelitian lain yang dilakukan oleh Potale dan Uhing (2015) dengan judul "Pengaruh Kompensasi dan Stres Kerja terhadap Kepuasan Kerja Karyawan Pada PT Bank Sulut Cabang Utama Manado". Hasil penelitian dan hipotesis menunjukan bahwa kompensasi dan stres kerja secara simultan berpengaruh secara signifikan terhadap kepuasan kerja.Secara parsial kedua variabel kompensasi dan stres kerja mempunyai pengaruh signifikan terhadap kepuasan kerja.Sebaiknya pimpinan PT Bank Sulut Cabang Utama dapat terus mempertahankan bahkan meningkatkan kepuasan karyawan sehingga tujuan utama dari organisasi bisa tercapai. 
Penelitian lain yang juga sejalan dengan penelitian ini adalah penelitian yang dilakukan oleh Supiyanto (2015) melakukan penelitian dengan judul "Pengaruh Kompensasi, Kompetensi dan Komitmen Organisasional terhadap Kepuasan Kerja dan Kinerja Karyawan Koperasi”. Temuan penelitian menunjukkan bahwa (1) kompensasi, kompetensi dan komitmen organisasi secara simultan berpengaruh signifikan terhadap kepuasan kerja karyawan; (2) kompensasi berpengaruh signifikan terhadap kepuasan kerja karyawan; (3) kompetensi berpengaruh signifikan terhadap kepuasan kerja karyawan; komitmen organisasional berpengaruh signifikan terhadap kepuasan kerja karyawan; (4) kompensasi, kompetensi, komitmen organisasi dan kepuasan kerja secara simultan berpengaruh signifikan terhadap kinerja karyawan; (5) kompensasi berpengaruh signifikan terhadap kinerja karyawan; (6) kompetensi berpengaruh tidak signifikan terhadap kinerja karyawan; (7) komitmen organisasi berpengaruh signifikan terhadap kinerja karyawan; dan (8) kepuasan kerja berpengaruh tidak signifikan terhadap kinerja karyawan.

Penelitian ini juga didukung oleh teori yang dikemukakan Sastrohadiwiryo (Sinambela, 2019) menyatakan bahwa kompensasi adalah imbalan jasa atau balas jasa yang diberikan oleh organisasi kepada para tenaga kerja karena tenaga kerja tersebut telah memberikan sumbangan tenaga dan pikiran demi kemajuan organisasi atau perusahaan guna mencapai tujuan yang telah di tetapkan. Keberhasilan dalam menentukan kompensasi yang layak akan menentukan bagaimana kualitas sumber daya manusia dalam bekerja, yang secara langsung akan berkaitan dengan efektivitas tujuan karyawan dan efisien anggaran organisasi, serta menentukan bagaimana keberlangsungan hidup organisasi dalam lingkungan persaingan yang semakin kompetitif. Kompensasi yang memadai akan mempengaruhi kinerja yang ditampilkan oleh para karyawan. Ketika kompensasi tidak sesuai dengan harapan para karyawan maka yang terjadi adalah penolakan secara halus sampai dengan penolakan secara keras melalui demonstrasi.

\section{Pengaruh Motivasi terhadap Kinerja Karyawan Melalui Kepuasan Kerja}

Berdasarkan hasil pengujian analisis jalur sub struktur pertama menunjukkan bahwa motivasi berpengaruh positif dan signifikan terhadap kepuasan kerja karyawan pada PT Matahari Departement Store Cabang Mall Panakkukang Makassar dengan tingkat pengaruh sebesar 28,2\%. Pada pengujian analisis jalur sub struktur kedua menunjukkan bahwa kompensasi berpengaruh positif dan signifikan terhadap kinerja karyawan pada PT Matahari Departement Store Cabang Mall Panakkukang Makassar dengan tingkat pengaruh sebesar 25,3\%. Total pengaruh (Total Effect) motivasi terhadap kinerja karyawan melalui kepuasan kerja dengan tingkat pengaruh sebesar 0,363 tau 36,3\%.

Hasil penelitian ini sejalan dengan penelitian lain yang dilakukan oleh Sugiyatmi, Minarsih, dan Edward (2016) dengan judul "Pengaruh Motivasi, Gaya Kepemimpin dan Lingkungan Kerja Terhadap Disiplin Kerja Serta Dampaknya terhadap Kinerja Karyawan Di PT Bina San Prima”. Hasil penelitian menunjukkan bahwa (1) Ada pengaruh variabel motivasi kerja terhadap Disiplin kerja karyawan pada PT Bina San Prima terbukti. (2) Ada pengaruh variabel Gaya Kepemimpinan terhadap Disiplin kerja karyawan PT Bina San Prima terbukti. (3) Ada pengaruh variabel Lingkungan kerja terhadap Disiplin kerja 
karyawan pada terbukti secara parsial berpengaruh positip dan signifikan terhadap disiplin kerja karyawan PT Bina San Prima Terbukti. Dan apabila Lingkungan kerja pada PT Bina San Prima Semarang. Baik maka disiplin kerjapun juga akan membaik. (4) Ada pengaruh variabel disiplin kerja terhadap kinerja karyawan PT Bina San Prima terbukti.

Penelitian lain yang juga sejalan adalah penelitian yang dilakukan oleh Hanafi (2017) dengan judul "Pengaruh Motivasi, dan Lingkungan Kerja, Terhadap Kinerja Karyawan, dengan Kepuasan Kerja sebagai Variabel Mediasi pada PT Bni Life Insurance”. Hasil penelitian menunjukan variabel motivasi terhadap kinerja karyawan berpengaruh positif dan signifikan karena memiliki nilai t-value $2.97>\mathrm{t}$-tabel 1.96. Begitupun motivasi terhadap kepuasan kerja memiliki nilai t value 2,31 > t-tabel 1.96 yang berarti motivasi berpengaruh positif dan signifikan terhadap kepuasan kerja. Motivasi terhadap kinerja karyawan yang dimediasi oleh kepuasan kerja juga berpengaruh signifikan dengan nilai t-value $-2.32>$ t-tabel 1.96. Namun pada variabel lingkungan kerja terhadap kinerja karyawan menunjukan tidak berpengaruh dan signifikan karena nilai t-value $0.00 \mathrm{t}$-tabel 1.96.Begitupun pada variabel lingkungan kerja terhadap kinerja karyawan dengan kepuasan kerja sebagai variabel mediasi mempunyai nilai t-value 3.36 > t-tabel 1.96 yang berarti bahwa kepuasan kerja positif memediasi hubungan antara lingkungan kerja terhadap kinerja karyawan. Terakhir dapat dilihat variabel kepuasan kerja terhadap kinerja karyawan dengan nilai t-value $-2.73>$ t-tabel 1.96, jadi dapat diartikan variabel kepuasan kerja berpengaruh positif dan signifikan terhadap kinerja karyawan.

Penelitian ini juga didukung oleh teori yang dikemukakan oleh Afandi (Lubis, Hermanto, Edison, 2018) mengatakan antara motivasi dan kepuasan kerja terdapat hubungan yang positif dan signifikan, karena kepuasan kerja mempunyai korelasi signifikan dengan motivasi. Atasan disarankan mempertimbangkan bagaiamana perilaku mereka mempengaruhi kepuasan pekerja sehingga mereka secara potensi dapat meningkatkan motivasi pekerja melalui berbagai usaha untuk meningkatkan kinerja mereka.

\section{PENUTUP}

\section{Kesimpulan}

Berdasarkan hasil penelitian yang telah diuraikan pada bab sebelumnya, maka kesimpulan dalam penelitian ini adalah sebagai berikut:

1. Lingkungan kerja berpengaruh positif dan signifikan terhadap kepuasan kerja karyawan pada PT Matahari Departement Store Cabang Mall Panakkukang Makassar.

2. Kompensasi berpengaruh positif dan signifikan terhadap kepuasan kerja karyawan pada PT Matahari Departement Store Cabang Mall Panakkukang Makassar.

3. Motivasi berpengaruh positif dan signifikan terhadap kepuasan kerja karyawan pada PT Matahari Departement Store Cabang Mall Panakkukang Makassar. 
4. Lingkungan kerja berpengaruh positif dan signifikan terhadap kinerja karyawan pada PT Matahari Departement Store Cabang Mall Panakkukang Makassar.

5. Kompensasi berpengaruh positif dan signifikan terhadap kinerja karyawan pada PT Matahari Departement Store Cabang Mall Panakkukang Makassar.

6. Motivasi berpengaruh positif dan signifikan terhadap kinerja karyawan pada PT Matahari Departement Store Cabang Mall Panakkukang Makassar.

7. Lingkungan kerja berpengaruh positif dan signifikan terhadap kinerja karyawan melalui kepuasan kerja pada PT Matahari Departement Store Cabang Mall Panakkukang Makassar.

8. Kompensasi berpengaruh positif dan signifikan terhadap kinerja karyawan melalui kepuasan kerja pada PT Matahari Departement Store Cabang Mall Panakkukang Makassar

9. Motivasi berpengaruh positif dan signifikan terhadap kinerja karyawan melalui kepuasan kerja pada Matahari Departement Store Cabang Mall Panakkukang Makassar.

\section{DAFTAR PUSTAKA}

Abadiyah R., Purwanto D. 2016. Pengaruh Budaya Organisasi, Kompensasi Terhadap Kepuasan Kerja dan Kinerja Karyawan Bank di Surabaya. Jurnal Bisnis, Manajemen \& Perbankan, Sidoarjo.

Badaruddin., Fatmasari. 2019. Manajemen Sumber Daya Manusia. Buku dua.

Badriyah M. 2015. Manajemen Sumber Daya Manusia. Cetakan kesatu. Bandung: Pustaka Setia.

Dwijayanti, NM., Dewi Kartika S.A.A. 2015. Pengaruh Kompensasi dan Lingkungan Kerja terhadap Kepuasan Kerja Karyawan pada Perusahaan Daerah Air Minum Tirta Mangutama Badung. E-Jurnal Unud, Vol 4. Bali.

Echdar. S. 2017.Metode Penelitian Manajemen dan Bisnis. Bogor: Ghalia Indonesia.

Edison E., Yohny A., Komariyah I., 2018. Manajemen Sumber Daya Manusia. Bandung: Alfabeta

Fahmi, I. 2017. Manajemen Sumber Daya Manusia. Cetakan kedua. Alfabeta. Bandung.

Hanafi DB., Yohana C. 2017. Pengaruh Motivasi dan Lingkungan Kerja Sebagai Variabel Mediasi pada PT BNI Lifeinsurance. Jurnal Pendidikan Ekonomi dan Bisnis Val 5, Jakarta

Handoko, Hani. 2014. Manajemen Personalia \& Sumber Daya Manusia. Cetakan Keduapuluh. Yogyakarta. 
Hardiyana A., Nurhadian FA., 2016. Pengaruh Kompensasi dan Motivasi Kerja terhadap Kepuasan Kerja serta Implikasinya pada Kinerja Karyawan. Jurnal Ekonomi, Bisnis \& Entrepreneurship vol 10. Bandung

Hasibuan, Malayu S.P. 2011. Manajemen Sumber Daya Manusia. Edisi Revisi. Jakarta: Penerbit Bumi Aksara

Hasibuan, S. P, Malayu. 2011. Manajemen: Dasar, Pengertian dan Masalah. Jakarta: Bumi Aksara.

Juliandi, Azwar. Beberapa Faktor Kepengurusan Kerja Yang Mempengaruhi Komitmen Organisasi (Studi Empiris Pada Para Dosen Fakultas Ekonomi Universitas Muhammadiyah Sumatera Utara). Tesis, Sekolah Pascasajrana Ilmu Manajemen Universitas Sumatera Utara. Medan. 2013.

Kadarisman, M. 2014. Manajemen Kompensasi. Jakarta: Rajawali.

Lubis, Y., Hermanto, B., Edison, E. 2018. Manajemen dan Riset Sumber Daya manusia. Cetakan kesatu. Bandung: Alfabeta.

Mangkunegara, A, P. 2015. Sumber Daya Manusia Perusahaan. Cetakan kesebelas. Remaja Rosdakarya: Bandung.

Manovia S. 2017. Strategi Kepemimpinan, Motivasi Kerja dan Kompensasi terhadap kepuasan Kerja serta Dampaknya Pada Kinerja Karyawan Generasi Y PT Bank BRI Wilayah I Jakarta. Jurnal Riset Perbankan Manajemen dan Akuntansi Vol.1. Jakarta.

Murty Windy Aprilia, hundiwinarsih Gusnati. 2012. Pengaruh Kompensasi, Motivasi dan Komitmen Organisasional terhadap Kinerja Karyawan bagian Akuntansi (Studi Kasus pada Perusahaan Manufaktur di Surabaya). Jurnal The Indonesian Accounting Review, 2(2),pp: 215;228.

Nancy LP., Tawas NH., 2016. Pengaruh Kompensasi dan Lingkungan Kerja terhadap Kepuasan Kerja dan Kinerja Pegawai. Jurnal EMBA Vol 4. Manado.

Noor, J. 2017. Metodologi Penelitian: Skripsi, Tesis, Disertasi, \& Karya Ilmiah. Jakarta. Kencana.

Notoatmodja, Soekidjo. 2009. Pengembangan Sumber Daya Manusia. Jakarta: Rineka Cipta

Nurtjahjono, G. E. (2014). Pengaruh Motivasi Kerja dan Lingkungan Kerja Terhadap Kinerja Karyawan. Jurnal Administrasi Bisnis, 13(1).

Nuryasin, I., Musadieq, M. Al, \& Ruhana, I. (2016). Pengaruh Lingkungan Kerja dan Motivasi Kerja Terhadap Kinerja Karyawan. Jurnal Administrasi Bisnis (JAB), 33(1), 52-60. 
Potale R., Uhing Y., Pengaruh Kompensasi dan Stress Kerja Terhadap Kepuasan Kerja Karyawan Pada PT Bank Sulut Cabang Utama Manado. Jurnal EMBA Vol 3. Manado.

Priansa, D, J. 2018. Perencanaan dan Pengembangan Sumber Daya Manusia. Cetakan ketiga. Bandung: Alfabeta.

Priansa, D,J., Suwanto. 2016. Manajemen Sumber Daya Manusia. Cetakan kelima. Bandung: Alfabeta.

Robbins, Stephen P. dan Coulter, Mary. 2010. Manajemen (edisi kesepuluh) Jakarta: Erlangga.

Sadili Samsudin. “Manajemen Sumber Daya Manusia”. 2012. Bandung : Pustaka Setia.

Saputra, Sigid Adri. 2010. Pengaruh Kompensasi, Kepuasan Kerja, Dan Motivasi Kinerja Terhadap Kinerja Karyawan Bagian Akuntansi Pada Perusahaan Umum Di Surabaya Dan Sidoarjo. Skripsi tidak diterbitkan. Surabaya: Program Pendidikan Strata Satu Sekolah Tinggi Ilmu Ekonomi.

Sedarmayanti, “Manajemen Sumber Daya Manusia Reformasi birokrasi dan Manajemen Pegawai Negeri Sipil”. Refika Aditama, Bandung, 2017.

Semardayanti. Tata Kerja dan Produktivitas Kerja. Bandung: CV. Mandar Maju. 2018.

Simaremare DC., Isyandi BH. 2015. Pengaruh Pelatihan, Lingkungan Kerja Fisik dan Non Fisik dan Kepemimpinan Terhadap Kepuasn Kerja dalam Meningkatkan Kinerja Karyawan Pada PT Federal Internasional Finance Wilayah Riau. Jurnal Tapak Manajemen Bisnis Vol VII. Riau.

Sinambela, L., P. 2019. Manajemen Sumber Daya Manusia: Membangun Tim Kerja Yang Solid untuk Meningkatkan Kinerja. Cetakan keempat. Jakarta: Bumi Aksara.

Sondang P Siagian. 2012. Teori Motivasi dan Aplikasinya Cetakan Keempat. Jakarta: Rineka Cipta

Sondang P, Siagian. 2014. Manajemen Sumber Daya Manusia. Jakarta: Bumi Aksara.

Sugiyatmi., Minarsih Magdelana M., P Edward Gagah PT. 2016. Pengaruh Motivasi, Gaya Kepemimpinan dan Lingkungan Kerja Terhadap Disiplin Kerja serta dampaknya terhadap Kinerja Karyawn di PT Bina San Prima. Journal Of Management Vol 2. Semarang.

Sugiyono. 2017. Statistika Untuk Penelitian. Bandung: Alfabeta.

Suntoyo, Danang. 2013. Manajemen Sumber Daya Manusia. CAPS. Jakarta.

Supiyanti Y. 2015. Pengaruh Kompensasi, Kompetensi dan Komitmen Organisasional terhadap Kepuasn Kerja dan Kinerja Karyawan Koperasi. Ronggolawe. 


\section{AkMen}

Volume 17 Nomor 3 September 2020

Hal. $393-407$

e-ISSN : 2621-4377 \& p-ISSN : 1829-8524

Hbmepage: https//e-jurnal.stienobel-indonesia.acid/index.php/akmen

Sutrisno. 2016. Manajemen Sumber Daya Manusia. Jakarta: Kencana Prenada Media Group.

Suwatno dan Donni Juni Priansa. 2011. Manajemen Sumber Daya Manusia Dalam Organisasi Publik dan Bisnis, cetakan pertama, Penerbit: Alfabeta, Bandung

Tampi, Bryan J, 2014. Pengaruh Gaya Kepemimpinan dan Motivasi Terhadap Kinerja pada PT. Bank Negara Indonesia, Tbk. Jurnal Acta Diurna, Vol. 3. No. 4.

Widodo, Suparno. 2015. Manajemen Pengembangan Sumber Daya Manusia. Yogyakarta: Pustaka Pelajar.

Yoesana, U. 2013. Hubungan Antara Motivasi Kerja dengan Disiplin Kerja Pegawai di Kantor Kecamatan Muara Jawa Kabupaten Kutai Kartanegara. e-Journal Pemerintahan Integratif, 1(1), 13-27. 